\title{
Advance of Novel Coronavirus Registration Clinical Trial
}

\section{Gao Song ${ }^{1, *}$, Meng Qun Cheng ${ }^{2, \dagger}$, Xian Wen Wei ${ }^{3, \dagger}$}

${ }^{1}$ Department of Pharmacy,The Puer People's Hospital of Yunna City, 44 Zhenxing Rd., Puer 665000, China;

${ }^{2}$ Department of Reproductive Medicine,The Puer People's Hospital of Yunna City, Puer 665000, China;

${ }^{3}$ Department of Neurology, The Puer People's Hospital of Yunna City, Puer 665000, China;

†These authors contributed equally to this work

*corresponding author:

Gao Song. Department of Pharmacy,The Puer People's Hospital of Yunna City, 44 Zhenxing Rd., Puer 665000, China;Tel: +86-0879-2121114; Fax: 0879-2141625;

Email: $387925693 @ q q . c o m$ 


\section{Abstract}

Background:To analyze the characteristics and heterogeneity of clinical trials of Novel Coronavirus(COVID-19) registered in the China Clinical Trial Registry (ChiCTR), and provide data bases and information references for clinical treatment

Methods:Statistics of COVID-19 clinical trials registered with ChiCTR as of February 24, 2020 were collected. Descriptive analysis of registration characteristics. The chi-square test is used to compare statistical differences between different study types, intervention methods, study stage, and Primary sponsor.

Results:232 COVID-19 studies registered at the ChiCTR were collected. The overall number of COVID-19 registrations was increased. Hubei Province, China has the largest number of registrations. There were significant differences between the number of participants $(\mathrm{P}=0.000)$, study duration $(\mathrm{P}=0.008)$, study assignment $(\mathrm{P}=0.000)$, and blind method $(\mathrm{P}=0.000)$ for different study types. Significant differences could be seen in the dimensions of multicenter study $(\mathrm{P}=0.022)$, of participants numbe $(\mathrm{P}=0.000)$, study duration $(\mathrm{P}=0.000)$ and study assignment $(\mathrm{P}=0.001)$ for the four intervention methods. There were significant differences in study assignment $(\mathrm{P}=0.043)$ between the early and late studies. CMT drugs with high research frequency are chloroquine, lopinavir / ritonavir, and I-IFN; BI was Cell therapy, plasma therapy, Thymosin, and M/P-AB.

Conclusions:Different study design characteristics have led to significant differences in some aspects of the COVID-19 clinical trial. Timely summary analysis can provide more treatment options and evidence for clinical practice.

Keywords: Coronavirus disease-19 (COVID-19); Drug Therapy; ChiCTR; Clinical Trial 


\section{Background}

Since the 1970s, more than 30 new types of infectious diseases, such as Ebola virus disease, human infection with highly pathogenic avian influenza, and Zika virus disease, have appeared in China, seriously threatening people's health and public health security [1,2]. The Novel coronavirus (COVID-19) is a new highly pathogenic coronavirus that broke out in Wuhan, China in December 2019. It can cause severe pneumonia and is listed as Public Health Emergency of International Concern (PHEIC) [3].

As of February 25, 2020, China has accumulated more than 70,000 confirmed cases of Novel coronavirus pneumonia(NCP), which have been reported internationally in 24 countries and 5 continents [4]. The timely conduct of clinical drug research and the promotion of clinical trial information sharing are critical to epidemic prevention and control.In May 2006, the World Health Organization (WHO) officially launched the International Clinical Trials Registry Platform (ICTRP). In July 2007, The ChiCTR was officially certified by the ICTRP as a first-level registrar, becoming the fourth primary registrar after the Australian/New Zealand Center, the American Center, and the British Center [5]. According to the Declaration of Helsinki and the regulations of National Medical Products Administration (NMPA), all medical research conducted in China must be registered in ChiCTR [6]. As of February 24, 2020, the ChiCTR Center has registered more than 200 COVID-19 clinical studies. It is of great significance to discuss the research status and development situation in this field in time, which is effective for conducting clinical research and accelerating the transformation of results.

Therefore, this study collates and analyzes the registration of COVID-19 clinical studies to provide an information-based data foundation and information reference for curbing the spread of COVID-19 epidemic.

\section{Methods}

\section{Data collection}

Check the "COVID-19 Clinical Research Index" issued by the ChiCTR Center, search the ChiCTR database with the keywords "Novel coronavirus" or "2019-nCoV" and count the registration information as of February 24, 2020. Extract the following information: (1) Registration status (date of registration, date of completion, region of registration, etc.). (2) Source of funds. (3) Recruitment status. (4) Ethical approval. (5) Data Management Committee. (6) Research types. (7) Research design. (8) Research stage. (9) Study time limit. (10) Number of participants. (11) Intervention methods. (12) Setting Blinding.Two reviewers (Gao Song and Mengqun Cheng) were transferred to SPSS and checked to determine the final 
dataset.There was no disagreement between the two reviewers about the dataset with 232 studies.

\section{Definitions}

Basic research characteristics: research type, intervention method, funding source and research stage. It is defined as: (1) Type of research: intervention, observation, prevention, diagnostic test, prognosis research. (2) Intervention methods: $\square$ Chemical treatment (CMT); $\square$ Biologics and immunoregulatory drugs (BI, such as cell therapy, antibodies and glucocorticoid); $\square$ Traditional Chinese Medicine Treatment (TCM, such as Chinese herbal medicine, proprietary Chinese medicines); $\square$ Behavioral intervention (BEI, such as cognitive, attitude, and behavioral interventions, exercise and psychological therapy, etc.); $\square$ no (missing information or not applicable [NA]). (3) funding source: industry (company, company), public (hospital, university, government), self-funding. (4) Research stage: early stages (stage $0, I, 1 / 2,2$ ), late stage (stage 3 or 4), and non-applicable stage. (5) Ethical approval: yes, no. (6) Data Management Committee: yes, no.

Study design characteristics: multicenter study, number of participants, study duration, study assignment, Blinding, and key inclusion/exclusion criteria. It is defined as: (1) Number of study locations: Single study location or Multiple study locations; (2) Number of participants: <100, 100 to 300, 301 to 1000,> 1000. (3) Study duration(month): <1, 1 to 3, 4 to 12,> 12. (4) Blind method: open, single blind, double blind, unspecified. (5) Study assignment: randomized, non-randomized, factorial grouping, continuous grouping, and others. (6) key inclusion/exclusion criteria: yes.

\section{Data analysis}

Descriptive analysis of registration time trends and geographical distribution, the registration volume reflects the overall trend of COVID-19 clinical research. Descriptive statistics were calculated to investigate the percentage distribution of all of the items studied.The frequency calculation of multi-center research institutions is based on the statistics of the responsible units. The study duration was calculated by ChiCTR's "Study execute time".Chi-square tests at the $95 \%$ significance level were then performed to study possible differences in design characteristics for research type, intervention method, funding source and research stage. In the chisquare test, we only statistically analyze the main features, excluding some feature analyses. Additionally, as $100.0 \%$ of the 232 studies had key inclusion/exclusion criteria, these items were ruled out in the chisquare tests. Statistical analysis was performed using SPSS22.0 software. $\mathrm{P}<0.05$ was considered statistically significant.

\section{Results}




\section{COVID-19 clinical study registration}

A total of 232 COVID-19 clinical studies were registered with ChiCTR. Overall, the number of registrations has increased steadily (Figure 1).The number of registrations before February 1 was small, and the number of registrations quickly increased to 8 on February 2, reaching a peak on February 14(n=18).On January 23, 2020, China's ChiCTR Center registered the first COVID-19 clinical study, and the intervention method was CMT treatment (ChiCTR2000029308).The first TCM clinical study was registered on January 27 (ChiCTR2000029381). The first BI study was registered on February 1 (ChiCTR2000029431). The BEI study was first registered on February 2.

As of the statistical date, a total of 18 provinces and 4 municipalities nationwide participated in the COVID-19 clinical study (Figure 2).The national registration volume ranked first in Hubei Province $(n=69,29.74 \%)$, followed by Guangdong Province $(n=29$, $12.50 \%)$, and Zhejiang Province and Sichuan Province tied for third place $(n=23$, 9.91\%).Tongji Hospital, Tongji Medical College, Huazhong University of Science and Technology is the most registered hospital( $\mathrm{n}=16)$.

\section{Heterogeneity analysis of study design features}

As shown in Table 1, 67.67\% of the studies were intervention studies and $25.00 \%$ were observational studies. $28.02 \%$ of the studies were treated with CMT, $12.93 \%$ were treated with BI, $28.02 \%$ were treated with TCM, and $8.62 \%$ were treated with BEI.The early stage accounted for $41.81 \%$ of all studies, and $20.69 \%$ of the studies were late stages. $53.88 \%$ of research is mainly funded by the public, and $57.76 \%$ of research is being recruited. However, $22.84 \%$ of the studies did not receive ethical approval, and $47.41 \%$ were not confirmed by the data management committee.

As shown in Table 2, only $6.47 \%$ of the studies were multicenter studies. $44.83 \%$ of the study participants were between 100 to 300 , and only $3.45 \%$ of the studies were $>1000$. $43.53 \%$ of the studies were completed within 4-12 months, and only $2.16 \%$ were completed within 1 month. $75.0 \%$ of the studies used random assignments, but $70.69 \%$ of the studies lacked information on blinding.

As shown in Table 3,the chisquare tests revealed significant differences in the design characteristics, depending on the Type of Study, for the items of participants number $(P=0.000)$, study duration $(P=0.008)$, study assignment $(P=0.000)$ and blind method $(P=0.000)$. The number of participants in $45.86 \%$ interventional and $43.10 \%$ observational studies was concentrated in the 100-300 range.46.50\% interventional and $37.93 \%$ observational studies were completed within $4-12$ months. $78.98 \%$ of the interventional 
studies were randomly assigned to the group, and $58.62 \%$ of the observations were continuous. Only $7.01 \%$ of interventional studies were blinded.

Significant differences could be seen in the dimensions of multicenter study $(P=0.022)$, of participants numbe $(P=0.000)$, study duration $(P=0.000)$ and study assignment $(P=0.001)$ for the four intervention methods.Only $1.54 \%$ of CMT studies are multi-center studies. Conversely, $20.00 \%$ of BEI studies are multi-center studies, accounting for the largest proportion.The number of participants mainly accounted for: $44.62 \%$ of CMT subjects were less than $100,80.00 \%$ of BI subjects were less than 100 , and $58.46 \%$ of TCM and $65.00 \%$ of BEI subjects were between 100 to 300 . The study period mainly focused on: $53.85 \%$ of the CMT studies were completed within 4 to 12 months, while $40.00 \%$ of the BIs were within 1 to $3,49.23 \%$ of the TCMs were within 4 to 12 , and $35.00 \%$ of the BEI studies were longer than 12 month.For study assignments, $76.92 \%$ of CMT, $70.00 \%$ of BI, $66.15 \%$ of TCM, and $40.00 \%$ of BEI studies were randomized. Only $7.69 \%$ of CMT, $13.34 \%$ of BI, and $3.08 \%$ of TCM were blinded in the study.

There were significant differences in the dimensions of study assignments $(P=0.043)$ in the early and late study stage. $60.82 \%$ of the early stages and $26.21 \%$ of the late stages were randomly assigned to the group. However, there were no significant differences in the main research dimensions of different funding sources $(P>0.05)$.

\section{Analysis of the characteristics of CMT and BI research}

All drugs involved in CMT and BI treatment research are summarized, and the frequency of research is recorded (the same drug is only recorded once in the same clinical trial).68.97\% of interventions were drug treatment $(\mathrm{n}=160)$. In the CMT study, the top three drugs studied by frequency: Chloroquine $(\mathrm{n}=16,16.84 \%)$, Lopinavir/ritonavir $(\mathrm{n}=15,15.79 \%)$, and I-IFN $(\mathrm{n}=11,11.58 \%)$.

In the BI study, the top three drugs in the study frequency were: cell therapy $(n=15$, $48.39 \%)$, plasma therapy $(n=5,16.13 \%)$, Thymosin $(n=2,6.45 \%)$ and M/P-AB $(n=2,6.45 \%)$. Among them, $32.26 \%$ of Cell therapy is mesenchymal stem cells, $9.68 \%$ of Cell therapy is Cord Blood Mononuclear Cell, 3.23\% of Cell therapy is Menstrual Blood-derived Stem Cells, and $3.23 \%$ of Cell therapy is Natural Killer Cell.Figure 3、4 and Table 4 for a summary of the high research frequency drugs for CMT and BI.

\section{Discussion}

Achieving information sharing in clinical trials is the key to accelerating the transformation of clinical resources and promoting scientific breakthroughs[7]. In the face of a public safety crisis such as an outbreak, the timely sharing of information is even more important, and it 
can provide real-time guidance for preventing and controlling the epidemic, assessing development trends and the effects of intervention measures[8].COVID-19's "war epidemic" and "epidemic prevention" strategies are closely related to the important measure of improving the transparency of clinical trials, including sharing of the subject's original data and standardizing trial design, registration, and implementation [9].

At present, China's clinical trial registration policy is to implement registration[10], which requires registration in accordance with the ChiCTR registration guidelines. The ChiCTR registration guidelines divide research types into 7 categories, such as interventional studies, preventive studies, diagnostic tests, and observational studies, etc.[11]. However, it is ambiguous that the registration guidelines classify studies by their nature and purpose. According to international standards, it may be more clear to classify intervention and observation [12].

In order to regulate registration, more details should be provided on the randomization procedure and blind method.We found that most interventional studies use randomized allocation, but there are low blinding rates and lack of information.The possible reason is that it is difficult to implement blind method in epidemic situation, but it may also be incomplete information. More than half of the studies did not indicate blind method information.Missing information means that no information about the size of the study is available, which adversely affects the transparency of registration[13].The results showed that more than half of the studies were not confirmed by the data management committee. Low blinding rate and lack of information may be related to it's. The detection or guidance of the data management committee should be further strengthened to improve the quality of research design[14].

It is worth noting that $22.84 \%$ of the studies failed ethical verification.All human-oriented clinical trials must in any case follow the "Helsinki Declaration", which has become a consensus of the medical community, and follow the basic ethical principle of "doctors should provide medical care in the best interests of patients" to ensure the subjects $[15,16]$.The ChiCTR Center has issued a warning and requested the supplementary information of the failed units to be reviewed.Medical ethics review should strictly abide by the review work content of the "Ethical Review Methods for Biomedical Research Involving Humans"[17], and here are two suggestions: (1) undertake experimental projects that match actual capabilities; (2) design of experimental schemes An appropriate research method must be selected based on the nature of the problem to be solved.

As of February 24, 2020, the overall number of COVID-19 registered clinical studies is on the rise.The possible reason is that China has already initiated a first-level response to 
major public health emergencies, and conducting relevant clinical trials is critical to epidemic prevention and control. In addition, in order to cooperate with the epidemic prevention and control work, many national drug clinical trial institutions(GCP) in China have established detailed work guidelines and guidelines to effectively speed up clinical trial review.From the statistical analysis of China's geographical distribution, it is found that the number of registered provinces in Hubei Province ranks first, and the number of registered provinces close to it is higher than that of other provinces. The possible reason is that the COVID-19 epidemic was mainly concentrated in Wuhan, Hubei Province, China. There was no large-scale epidemic outbreak in remote provinces, and there were relatively few NCP patients.

We found significant differences in the dimension of study design characteristics for different study types. The results showed that compared to observational studies, most interventional studies had fewer than 100 participants. However, $8.62 \%$ of observational study designs were completed within 1 month. Such designs were not reflected in interventional studies, and most of the interventional studies were completed in 4-12 months. Similarly, compared to observational studies, most interventional studies use randomized allocation. These results imply that different interventions have an impact on the design of clinical trials.

The design of COVID-19 clinical trials should give priority to "timeliness". The trial sample size needs to consider the balance between clinical and statistical significance, and its estimated volume reflects the reliability and repeatability of the research results[18].As public health emergencies do not allow more time for exploratory clinical research and there is no historical data, the sample size estimation of such trials may encounter unprecedented problems.Some scholars have proposed[19], whether it is possible to reduce the required sample size by "reducing the power" or "increasing the type I error rate" to complete the clinical trial as soon as possible?But such an approach requires a variety of trade-offs between regulators, sponsors, and researchers.

In addition, the study period is also "time-effective". If a clinical study is long, it may not make much sense in terms of public health emergencies to respond to the outbreak. From the statistical data, it can be seen that the time limit for completing most of the clinical studies of COVID-19 is concentrated within 4-12 months, and very few studies are completed within 1 month. The clinical research to deal with the epidemic is to race against the virus and the epidemic. This time limit seems too long. Is it possible to conduct mid-term analysis or other adaptive, new design methods? Clinical trial statistics need to be continuously developed 
based on actual needs.

In addition to the prevention and control of the epidemic, vaccines and drugs are the two major weapons to overcome the epidemic.The previous SARS-CoV epidemic, the 2009 influenza epidemic, and the Ebola epidemic in West Africa were basically approved for marketing at the end of the epidemic, with a lag[20,21].Similarly, the development of specific drugs is also very difficult.The "old medicine" is a new way to increase the indications, and conducting clinical research on anti-COVID-19 may be an important means to respond to the current epidemic.

The "New Coronary Virus Pneumonia Diagnosis and Treatment Scheme (Trial Version 6)" (hereinafter referred to as the "Scheme") states that there are currently no effective drugs to treat NCP patients.

Drugs such as lopinavir / ritonavir, interferon, abidol, and chloroquine phosphate can be tried, but their effectiveness needs to be confirmed in clinical studies.In the registration trial, the main treatment was drug therapy, accounting for $68.97 \%$. Among them, there are more CMT and TCM studies, and relatively few BI studies. The most frequently studied CMT is chloroquine phosphate.Chloroquine phosphate is an antimalarial drug marketed for many years, and it has been reported in the literature[22] that it can interfere with the glycosylation of the ACE2 receptor, thereby exerting antiviral effects.In vitro experiments show that chloroquine phosphate has the activity of inhibiting COVID-19, and its half effective concentration (EC50) is $1.13 \mu / \mathrm{moL}$ [23].As of February 24, 16 clinical studies of chloroquine phosphate-based NCP have registered clinical trials with ChiCTR. Chloroquine phosphate may have clinical therapeutic value.

Mesenchymal stem cells are the most frequently studied in immunotherapy $(n=10)$. Immune abnormalities are the main reason for the progression of patients with severe new-type coronavirus pneumonia. MSC can regulate both the innate immune system and the acquired immune system, and has become the most promising treatment for immune disorders[24,25].MSC can regulate inflammation through a series of mechanisms, including inhibiting $\mathrm{T}$ cell hyperproliferation, inducing $\mathrm{CD} 4^{+} \mathrm{CD} 25^{+} \mathrm{FoxP} 3^{+}$regulatory $\mathrm{T}$ cell (Tregs) subsets, and also inhibiting B cell hyperproliferation, differentiation, and immunoglobulin production[26]. At the same time, it can also regulate the secretion of major inflammatory factors and anti-inflammatory factors[27].Immunotherapy of MSC may have clinical therapeutic value.

The "Scheme" emphasizes the important role of TCM. The treatment of the "pathogenic factor" the mechanism by which TCM treats the cause of COVID-19[28]. In addition, its 
multi-target regulation of the body's immune system has a therapeutic effect on "cytokine storm" [29]. Currently, relevant clinical studies have confirmed the effectiveness of TCM[30], but further validation by large-scale RCT is needed. Chinese scholars[31] have counted the research frequency of TCM, this article does not count.

BEI research also plays an important role. The rapid implementation of BEI intervention strategies in the early stages of the epidemic can effectively control the spread of the epidemic[32-35]. The main strategies are: (1) Early effective risk communication, timely understanding of the relevant knowledge, knowledge, attitudes and behaviors of the public, and health education. (2) Restrict the travel of people in key areas and mobilize the whole society.

This study has some limitations. The data for this study were derived only from ChiCTR. There may be other databases containing COVID-19 clinical studies. The time limit for research registration is short, and relevant registration information has not been filled in, and it cannot truly reflect its true quantity and level. However, the innovation of this article is to summarize and analyze the registration of ChiCTR's COVID-19 clinical research in a timely manner, reflecting the research status and development trend of clinical trials in this field, which is "time-effective".

\section{Conclusion}

There were problems of unclear classification of research types and irregular registration behavior. Also, within the studies researched, heterogeneity exists for various dimensions. Different research types, intervention methods, and research stages lead to significant differences in some dimensions of the COVID-19 study. Finally, statistical high-frequency research drugs can provide more treatment options and evidence-based evidence for the clinical practice.

\section{Abbreviations}

COVID-19:Corona virus disease 2019; ChiCTR:China Clinical Trial Registry; PHEIC:Public Health Emergency of International Concern; NCP:Novel coronavirus pneumonia; ICTRP:International Clinical Trials Registry Platform; CMT:Chemical treatment; BI:Biologics and immunoregulatory drugs; TCM:Traditional Chinese Medicine Treatment; GCP:National Drug Clinical Trial Institutions; I-IFN:I-Interferon; PD-1:CD279; $\mathrm{M} / \mathrm{P}-\mathrm{AB}=$ Monoclonal/Polyclonal Antibodies; $\mathrm{vMIP}=$ Virus macrophage inflammatory protein; $\mathrm{hFABP}=$ Heart fatty acid binding protein; G-CSF=granulocyte colony stimulating factor; $\mathrm{BPHP}=$ biological preparation of human placenta; FDPG=Anti-aging Active Freeze-dried Powder Granules. 


\section{Acknowledgements}

Not applicable.

\section{Authors' contributions}

XWW and MQC contributed to research design. GS and MQC search and extract data from the database. GS helps with data analysis. GS and MQC drafted the manuscript. GS and MQC revised the manuscript. The final draft read and endorsed by all authors

\section{Funding}

No funding was received for this study.

\section{Availability of data and materials}

Not applicable.

\section{Ethics approval and consent to participate}

Not applicable.

\section{Consent for publication}

Not applicable.

\section{Competing interests}

The authors declare that they have no competing interests.

\section{Author details}

${ }^{1}$ Department of Pharmacy,The Puer People's Hospital of Yunna City, 44 Zhenxing Rd., Puer 665000, China. ${ }^{2}$ Department of Reproductive Medicine, The Puer People's Hospital of Yunna City, Puer 665000, China. ${ }^{3}$ Department of Neurology, The Puer People's Hospital of Yunna City, Puer 665000, China;

\section{References}

1.Wu T, Perrings C, Kinzig A, et al. Economic growth, urbanization, globalization, and the risks of emerging infectious diseases in China: a review[J]. Ambio, 2017, 46(1): 18-29.

2.XU Yi. Several emergency and re-emerging infectious diseases[J]. Chinese Journal of Practical Pediatrics, 2018, 33(6):426-430.

3.Zhu N, Zhang D, Wang W, et al. A novel coronavirus from patients with pneumonia in China, 2019[J]. New England Journal of Medicine, 2020. 
4.National Health and Health Commission of the people's Republic of China. Update on the 2019 Novel Coronavirus in China 02/20/2020 24:00[EB/OL] [2020-02-20].http://www.nhc.gov.cn/xcs/yqfkdt/202002/ac1e98495cb04d36b0d0a4e1e7fab54 5.shtml.

5.MINAWAER Abudu, HAO Yuan, KONG Xiangyu, CHEN Shuo,LI Youping,WU Taixiang. The past 10 years of clinical trial registration in China: Status ans Challenge[J]. CHINESE JOURNAL OF EVIDENCE-BASED MEDICINE, 2018(6):522-525

6.ZHANG Ting, LI Wanling, CHEN Lei. Analysis of hypertension-related clinical trial registration in China based on ClinicalTrials.gov and Chinese Clinical Trial Registry database[J]. West China Medical Journal, 2019, 34(04):419-424.

7.Kochhar S, Knoppers B, Gamble C, et al. Clinical trial data sharing: here's the challenge[J]. BMJ open, 2019, 9(8): e032334.

8.Heymann D L. Data sharing and outbreaks: best practice exemplified[J]. The Lancet, 2020, 395(10223): 469-470.

9.Taichman D B , Sahni P, Pinborg A, et al. Data sharing statements for clinical trials[J]. Bmj Clinical Research, 2017, 357:j2372.

10.WU Taixiang, BIAN Zhaoxiang, LI Youping, SHANG Hongcail. Promoting standardization of clinical trial data management in China[J]. CHINESE JOURNAL OF EVIDENCE-BASED MEDICINE, 2018(6):532-537.

11.Yao C, Sugino K, Qian G. Current status of multinational clinical trials in east asia[J]. Chin J Evid-based Med, 2010, 10(2): 122-128.

12.Bhaskar S B. Clinical trial registration: A practical perspective[J]. Indian journal of anaesthesia, 2018, 62(1): 10.

13.Rochon P A, Stall N M, Savage R D, et al. Transparency in clinical trial reporting[J]. 2018. 14.Nourani A, Ayatollahi H, Dodaran M S. Clinical Trial Data Management Software: A Review of the Technical Features[J]. Reviews on recent clinical trials, 2019, 14(3): 160-172.

15.World Medical Association. Helsinki Declaration of the World Medical Association (2013 edition)[C].64th World Congress of Medical Associations, Brazil: Fortaleza,2013.10.

16.Chengchun Sun. Discussion on Ethical Problems and Countermeasures in Clinical Medical Research[J].Chinese Journal of Medical Scientific Research Management, 2016 (004): 244-247.

17.ZHANG Hai-hong. Discussion on the Core Ethical Issues in Global Health Emergencies[J]. Medicine \& Philosophy, 2019 (14): 1.

18.Abbas I. Hybrid research simulation modeling for making decisions on sample size and power of randomized clinical trials considering expected net benefits[C]//2017 Winter Simulation Conference (WSC). IEEE, 2017: 2845-2856. 
19.center for drug evaluation , NMPA(CHINA).Comprehensive review report on application for production of $\mathrm{H} 1 \mathrm{~N} 1$ influenza virus split vaccine[EB/OL].[2020-02-17].http://www.cde.org.cn/news.do?method=largeInfo\&id=311493

20.Chen Pingyan. Statistical considerations for sample size determination in clinical trials[J]. China Health Statistics, 2015, 032(004):727-731,733.

21.US Food and Drug Administration. First FDA-approved vaccine for the prevention of Ebola virus disease, marking a critical milestone in public health preparedness and response[J]. Press Announc, 2019.

22.Vincent M J, Bergeron E, Benjannet S, et al. Chloroquine is a potent inhibitor of SARS coronavirus infection and spread[J]. Virology journal, 2005, 2(1): 69.

23.Wang M, Cao R, Zhang L, et al. Remdesivir and chloroquine effectively inhibit the recently emerged novel coronavirus (2019-nCoV) in vitro[J]. Cell Research, 2020: 1-3.

24.Uccelli A, Moretta L, Pistoia V. Mesenchymal stem cells in health and disease[J]. Nature reviews immunology, 2008, 8(9): 726-736.

25.Nauta, A.J. and W.E. Fibbe, Immunomodulatory properties of mesenchymal stromal cells. Blood, The Journal of the American Society of Hematology, 2007. 110(10): p. 3499-3506.

26.Uccelli, A. and N.K. de Rosbo, The immunomodulatory function of mesenchymal stem cells: mode of action and pathways. Annals of the New York Academy of Sciences, 2015. 1351(1): p. 114-126.

27.Ben-Mordechai T, Palevski D, Glucksam-Galnoy Y, et al. Targeting macrophage subsets for infarct repair[J]. Journal of cardiovascular pharmacology and therapeutics, 2015, 20(1): $36-51$.

28.ZOU Lu, YU Xiao, WU Yuqin, SUN Ding, WU Yin'gen, FANG Hong. Analysis and thinking on traditional Chinese medicine in preventing and treating severe cases of novel coronavirus pneumonia.[J/OL].Academic Journal of Shanghai University of Traditional Chinese Medicine:1-6[2020-02-29].https://doi.org/10.16306/j.1008-861x.2020.02.002.

29.YIN Ming-xing, CAO Yan, SHI Chun-yang, WANG Wen-qing, FANG Jian-guo. Research progress of prevention and treatment of cytokine storm with traditional Chinese medicine[J/OL].Chinese Traditional and Herbal Drugs:1-7[2020-02-29].http://kns.cnki.net/kcms/detail/12.1108.R.20200227.1610.002.html. 30.State Administration of Traditional Chinese Medicine of the People's Republic of China.Progress in screening of effective prescriptions of traditional Chinese medicine[EB/OL].

( 2020-02-06 ) .http://bgs.satcm.gov.cn/gongzuodongtai/2020-02-06/12866.html.

31.SHAO Zhong-bai, ZHU Yue-xia, LIU Shu-hao, JIANG Kai-jun, WU Qi, SHEN Jin-yang, 
LIU Wei-wei. A review on the clinical application of high frequency traditional Chinese medicine in the treatment of new coronavirus pneumonia[J/OL].Chinese Traditional and Herbal

Drugs:1-6[2020-02-29].http://kns.cnki.net/kcms/detail/12.1108.R.20200225.1433.006.html. 32.Liu W, Zhang Y, Cai S, et al. The Study of Infectious Disease Outbreaks Based on Complex Behavior Response[J]. Complex Systems and Complexity Science, 2017, 14(1):8-14.

33.Hui D S, I Azhar E, Madani T A, et al. The continuing 2019-nCoV epidemic threat of novel coronaviruses to global health-The latest 2019 novel coronavirus outbreak in Wuhan, China[J]. International Journal of Infectious Diseases, 2020, 91: 264-266.

34.Cheng V C C, Wong S C, To K K W, et al. Preparedness and proactive infection control measures against the emerging Wuhan coronavirus pneumonia in China[J]. Journal of Hospital Infection, 2020.

35.QI Ye, CHEN Liu-huan, ZHANG Li, YANG Ying-ying, ZHAN Si-yi, FU Chuan-xi.Public practice, attitude and knowledge of Novel Coronavirus-Infected Pneumonia[J/OL].Journal of Tropical

Medicine,2020(02):1-12[2020-02-28].http://kns.cnki.net/kcms/detail/44.1503.R.20200204.11 14.002.html. 
medRxiv preprint doi: https://doi.org/10.1101/2020.03.16.20034934; this version posted August 13, 2020. The copyright holder for this preprint (which was not certified by peer review) is the author/funder, who has granted medRxiv a license to display the preprint in perpetuity.

All rights reserved. No reuse allowed without permission.

Table 1 Basic characteristics of COVID-19 registered clinical trials

\begin{tabular}{|c|c|}
\hline & $\mathrm{N}=232$ \\
\hline \multicolumn{2}{|l|}{ Type of Study } \\
\hline Interventional & $157(67.67 \%)$ \\
\hline Observational & $58(25.00 \%)$ \\
\hline Diagnostic experiment & $12(5.17 \%)$ \\
\hline Prognose study & $3(1.29 \%)$ \\
\hline Preventive research & $2(0.86 \%)$ \\
\hline \multicolumn{2}{|l|}{ Intervention model } \\
\hline CMT & $65(28.02 \%)$ \\
\hline BI & $30(12.93 \%)$ \\
\hline $\mathrm{TCM}$ & $65(28.02 \%)$ \\
\hline BEI & $20(8.62 \%)$ \\
\hline N/A & $52(22.41 \%)$ \\
\hline \multicolumn{2}{|l|}{ Stage of Study } \\
\hline Early stage $(0$, I , II ) & $97(41.81 \%)$ \\
\hline Late stage ( III , IV ) & $48(20.69 \%)$ \\
\hline Not applicable stage & $87(37.50 \%)$ \\
\hline \multicolumn{2}{|l|}{ Primary sponsor } \\
\hline Industry & $10(4.31 \%)$ \\
\hline Public & $125(53.88 \%)$ \\
\hline Self-paying & $97(41.81 \%)$ \\
\hline \multicolumn{2}{|l|}{ Recruiting status } \\
\hline Actively recruiting & $134(57.76 \%)$ \\
\hline Not yet open for recruitment & $98(42.24 \%)$ \\
\hline \multicolumn{2}{|l|}{ Ethical approval } \\
\hline Yes & $179(77.16 \%)$ \\
\hline No & $53(22.84 \%)$ \\
\hline \multicolumn{2}{|l|}{ Data Management Committee } \\
\hline Yes & $122(52.59 \%)$ \\
\hline No & $110(47.41 \%)$ \\
\hline
\end{tabular}


medRxiv preprint doi: https://doi.org/10.1101/2020.03.16.20034934; this version posted August 13, 2020. The copyright holder for this preprint (which was not certified by peer review) is the author/funder, who has granted medRxiv a license to display the preprint in perpetuity.

All rights reserved. No reuse allowed without permission.

Table 2 Design features of COVID-19 registered clinical trial

$\mathrm{N}=232$

Number of study locations

Single study location

$217(93.53 \%)$

Multiple study locations

$15(6.47 \%)$

Participant number

$$
<100
$$

$81(34.91 \%)$

$100 \sim 300$

$104(44.83 \%)$

301 1000

$37(15.95 \%)$

$>1000$

$8(3.45 \%)$

missing

$2(0.86 \%)$

Study period ( MO )

$\begin{array}{cr}<1 & 5(2.16 \%) \\ 1 \sim 3 & 78(33.62 \%) \\ 4 \sim 12 & 101(43.53 \%) \\ >12 & 34(14.66 \%) \\ \text { Missing } & 14(6.03 \%)\end{array}$

Study Assignment

\section{Randomized}

$126(54.31 \%)$

Nonrandomized

$20(8.62 \%)$

Sequential

44(18.97\%)

Factorial

26(11.21\%)

others

$16(6.90 \%)$

Blinding

$$
\text { Open }
$$

Single blind

$4(1.72 \%)$

Double blind

$8(3.45 \%)$

Missing

164(70.69\%)

Key inclusion/exclusion criteria 
Table 3 Design characteristic differences among Basic characteristics of COVID-19 registered clinical trials

\begin{tabular}{|c|c|c|c|c|c|c|c|c|c|c|c|}
\hline & \multicolumn{2}{|c|}{ Type of Study } & \multicolumn{4}{|c|}{ Intervention model } & \multicolumn{2}{|c|}{ stage } & \multicolumn{3}{|c|}{ Primary sponsor } \\
\hline & $\begin{array}{c}\text { Interventional } \\
(\mathrm{n}=157)\end{array}$ & $\begin{array}{c}\text { Observational } \\
\qquad(\mathrm{n}=58)\end{array}$ & $\begin{array}{c}\text { CMI } \\
(n=65)\end{array}$ & $\begin{array}{c}\text { BI } \\
(\mathrm{n}=30)\end{array}$ & $\begin{array}{c}\text { TCM } \\
(\mathrm{n}=65)\end{array}$ & $\begin{array}{c}\text { BEI } \\
(\mathrm{n}=20)\end{array}$ & $\begin{array}{l}\text { Early stage } \\
\qquad(\mathrm{n}=97)\end{array}$ & $\begin{array}{l}\text { Late stage } \\
(\mathrm{n}=48)\end{array}$ & $\begin{array}{l}\text { Industry } \\
(\mathrm{n}=10)\end{array}$ & $\begin{array}{c}\text { Public } \\
(\mathrm{n}=125)\end{array}$ & $\begin{array}{c}\text { Self-paying } \\
(\mathrm{n}=97)\end{array}$ \\
\hline \multicolumn{12}{|l|}{ Number of study locations ${ }^{b}$} \\
\hline Single study location & $145(92.36 \%)$ & $55(94.83 \%)$ & $64(98.46 \%)$ & $28(93.33 \%)$ & $58(89.23 \%)$ & $16(80.00 \%)$ & $88(90.72 \%)$ & $47(97.92 \%)$ & $10(100.00 \%)$ & $117(93.60 \%)$ & $90(92.78 \%)$ \\
\hline Multiple study locations & $12(7.64 \%)$ & $3(5.17 \%)$ & $1(1.54 \%)$ & $2(6.67 \%)$ & $7(10.77 \%)$ & $4(20.00 \%)$ & $9(9.28 \%)$ & $1(2.08 \%)$ & $0(0.00 \%)$ & $8(6.40 \%)$ & $7(7.22 \%)$ \\
\hline \multicolumn{12}{|l|}{ Participant numbera ${ }^{\alpha, b}$} \\
\hline$<100$ & $66(42.04 \%)$ & $11(18.97 \%)$ & $29(44.62 \%)$ & $24(80.00 \%)$ & $11(16.92 \%)$ & $4(20.00 \%)$ & $43(44.33 \%)$ & $15(31.25 \%)$ & $5(50.00 \%)$ & $34(27.20 \%)$ & $42(43.30 \%)$ \\
\hline $100 \sim 300$ & $72(45.86 \%)$ & $25(43.10 \%)$ & $28(43.08 \%)$ & $6(20.00 \%)$ & $38(58.46 \%)$ & $13(65.00 \%)$ & $40(41.24 \%)$ & $24(50.00 \%)$ & $2(20.00 \%)$ & $61(48.80 \%)$ & $41(42.27 \%)$ \\
\hline $301 \sim 1000$ & $18(11.46 \%)$ & $15(25.86 \%)$ & $8(12.31 \%)$ & $0(0.00 \%)$ & $15(23.08 \%)$ & $1(5.00 \%)$ & $12(12.37 \%)$ & $9(18.75 \%)$ & $3(30.00 \%)$ & $21(16.80 \%)$ & $13(13.40 \%)$ \\
\hline$>1000$ & $1(0.64 \%)$ & $6(10.34 \%)$ & $0(0.00 \%)$ & $0(0.00 \%)$ & $1(1.54 \%)$ & $2(10.00 \%)$ & $2(2.06 \%)$ & $0(0.00 \%)$ & $0(0.00 \%)$ & $7(5.60 \%)$ & $1(1.03 \%)$ \\
\hline Missing & $0(0.00 \%)$ & $1(1.72 \%)$ & $0(0.00 \%)$ & $0(0.00 \%)$ & $0(0.00 \%)$ & $0(0.00 \%)$ & $0(0.00 \%)$ & $0(0.00 \%)$ & $0(0.00 \%)$ & $2(1.60 \%)$ & $0(0.00 \%)$ \\
\hline \multicolumn{12}{|l|}{ Study duration $(\mathrm{MO})^{\alpha, b}$} \\
\hline$<1$ & $0(0.00 \%)$ & $5(8.62 \%)$ & $1(1.54 \%)$ & $7(23.33 \%)$ & $0(0.00 \%)$ & $1(5.00 \%)$ & $0(0.00 \%)$ & $0(0.00 \%)$ & $0(0.00 \%)$ & $2(1.60 \%)$ & $3(3.09 \%)$ \\
\hline $1 \sim 3$ & $51(32.48 \%)$ & $18(31.03 \%)$ & $24(36.92 \%)$ & $12(40.00 \%)$ & $21(32.31 \%)$ & $6(30.00 \%)$ & $31(31.96 \%)$ & $17(35.42 \%)$ & $2(20.00 \%)$ & $42(33.60 \%)$ & $34(35.05 \%)$ \\
\hline $4 \sim 12$ & $73(46.50 \%)$ & $22(37.93 \%)$ & $35(53.85 \%)$ & $9(30.00 \%)$ & $32(49.23 \%)$ & $5(25.00 \%)$ & $41(42.27 \%)$ & $22(25.83 \%)$ & $6(60.00 \%)$ & $56(44.80 \%)$ & $40(41.24 \%)$ \\
\hline$>12$ & $25(15.92 \%)$ & $8(13.79 \%)$ & $2(3.08 \%)$ & $0(0.00 \%)$ & $8(12.31 \%)$ & $7(35.00 \%)$ & $21(21.65 \%)$ & $5(10.42 \%)$ & $1(10.00 \%)$ & $19(15.20 \%)$ & $13(13.40 \%)$ \\
\hline Missing & $8(5.10 \%)$ & $5(8.62 \%)$ & $3(4.62 \%)$ & $2(6.67 \%)$ & $4(6.15 \%)$ & $1(5.00 \%)$ & $4(4.12 \%)$ & $4(8.33 \%)$ & $1(10.00 \%)$ & $6(4.80 \%)$ & $7(7.22 \%)$ \\
\hline \multicolumn{12}{|l|}{ Study Assignment ${ }^{a, b, c}$} \\
\hline Randomized & $124(78.98 \%)$ & $1(1.72 \%)$ & $50(76.92 \%)$ & $21(70.00 \%)$ & $43(66.15 \%)$ & $8(40.00 \%)$ & $59(60.82 \%)$ & $38(79.17 \%)$ & $6(60.00 \%)$ & $66(52.80 \%)$ & $54(55.67 \%)$ \\
\hline Nonrandomized & $17(10.83 \%)$ & $2(3.45 \%)$ & $6(9.23 \%)$ & $2(6.67 \%)$ & $10(15.38 \%)$ & $2(10.00 \%)$ & $8(8.25 \%)$ & $6(12.50 \%)$ & $1(10.00 \%)$ & $10(8.00 \%)$ & $9(9.28 \%)$ \\
\hline
\end{tabular}




\begin{tabular}{|c|c|c|c|c|c|c|c|c|c|c|c|}
\hline Sequential & $2(1.28 \%)$ & $34(58.62 \%)$ & $2(3.08 \%)$ & $3(10.00 \%)$ & $6(9.23 \%)$ & $4(20.00 \%)$ & $15(15.46 \%)$ & $2(4.17 \%)$ & $0(0.00 \%)$ & $23(18.40 \%)$ & $21(21.65 \%)$ \\
\hline Factorial & $4(2.55 \%)$ & $17(29.31 \%)$ & $3(4.62 \%)$ & $0(0.00 \%)$ & $1(1.54 \%)$ & $5(25.00 \%)$ & $11(11.34 \%)$ & $1(2.08 \%)$ & $0(0.00 \%)$ & $17(13.60 \%)$ & $9(9.28 \%)$ \\
\hline others & $10(6.37 \%)$ & $4(6.90 \%)$ & $4(6.15 \%)$ & $4(13.33 \%)$ & $5(7.69 \%)$ & $1(5.00 \%)$ & $4(4.12 \%)$ & $1(2.08 \%)$ & $3(30.00 \%)$ & $9(7.20 \%)$ & $4(4.12 \%)$ \\
\hline \multicolumn{12}{|l|}{ Blinding $^{\alpha}$} \\
\hline Open & $54(34.39 \%)$ & $2(3.45 \%)$ & $22(33.85 \%)$ & $10(33.33 \%)$ & $17(26.15 \%)$ & $6(30.00 \%)$ & $29(20.62 \%)$ & $19(39.58 \%)$ & $5(50.00 \%)$ & $22(17.60 \%)$ & $29(29.90 \%)$ \\
\hline Single blind & $3(1.91 \%)$ & $0(0.00 \%)$ & $1(1.54 \%)$ & $2(6.67 \%)$ & $0(0.00 \%)$ & $0(0.00 \%)$ & $4(4.12 \%)$ & $0(0.00 \%)$ & $0(0.00 \%)$ & $1(0.80 \%)$ & $3(3.09 \%)$ \\
\hline Double blind & $8(5.10 \%)$ & $0(0.00 \%)$ & $4(6.15 \%)$ & $2(6.67 \%)$ & $2(3.08 \%)$ & $0(0.00 \%)$ & $3(3.09 \%)$ & $5(10.42 \%)$ & $0(0.00 \%)$ & $4(3.20 \%)$ & $4(4.12 \%)$ \\
\hline Missing & $92(58.60 \%)$ & $56(96.55 \%)$ & $38(58.46 \%)$ & $16(53.33 \%)$ & $46(70.77 \%)$ & $14(70.00 \%)$ & $61(62.89 \%)$ & $24(50.00 \%)$ & $5(50.00 \%)$ & $98(78.40 \%)$ & $61(62.89 \%)$ \\
\hline
\end{tabular}

${ }^{\alpha} \mathrm{P}<0.05$ : Type of Study; ${ }^{\mathrm{b}} \mathrm{P}<0.05$ : Intervention model; ${ }^{\mathrm{c}} \mathrm{P}<0.05$ : stage; ${ }^{\mathrm{d}} \mathrm{P}<0.05$ : Primary sponsor 
Table 4 CMT and BI studies in the clinical registry for the treatment of COVID-19 infection

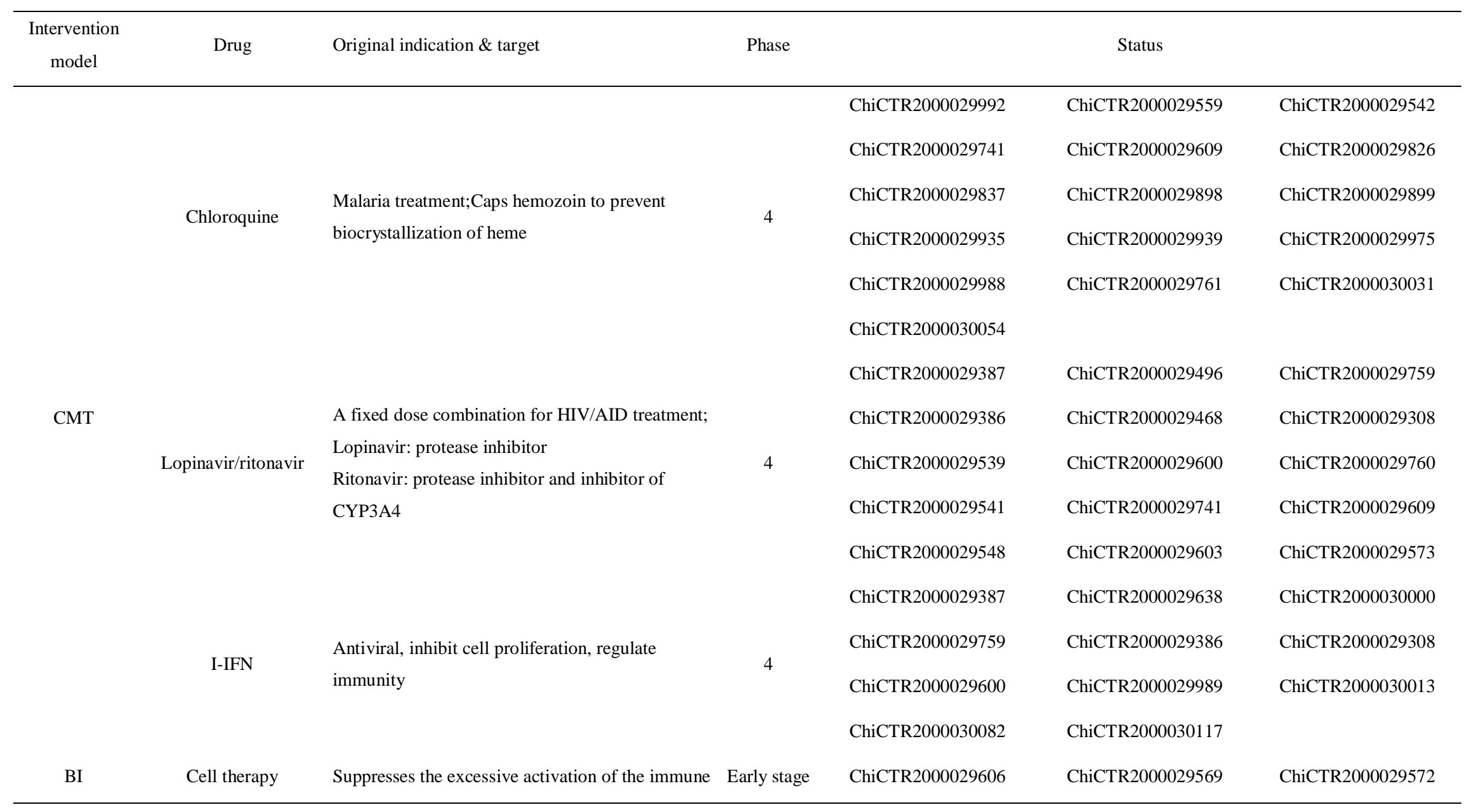




\begin{tabular}{|c|c|c|c|c|c|}
\hline & \multicolumn{2}{|l|}{ system } & ChiCTR2000029580 & ChiCTR2000029812 & ChiCTR2000029816 \\
\hline & & & ChiCTR2000029817 & ChiCTR2000029991 & ChiCTR2000030116 \\
\hline & & & ChiCTR2000029818 & ChiCTR2000030020 & ChiCTR2000030138 \\
\hline & & & ChiCTR2000029990 & ChiCTR2000030088 & \\
\hline \multirow{2}{*}{ Plasma therapy } & \multirow{2}{*}{ Passive immunity } & \multirow{2}{*}{ Early stage } & ChiCTR2000029757 & ChiCTR2000029850 & ChiCTR2000030010 \\
\hline & & & ChiCTR2000030039 & ChiCTR2000030046 & \\
\hline Thymosin & $\begin{array}{l}\text { Promote T-lymphocytes to mature with regulation } \\
\text { And enhance the immune function of human cells }\end{array}$ & $\begin{array}{c}\text { Not } \\
\text { applicable } \\
\text { stage }\end{array}$ & ChiCTR2000029806 & ChiCTR2000029541 & \\
\hline $\mathrm{M} / \mathrm{P}-\mathrm{AB}$ & Specific binding & Early stage & ChiCTR2000030089 & ChiCTR2000030012 & \\
\hline
\end{tabular}


Figure1.Trend of registration time for COVID-19 clinical studies.

Figure2.Regional distribution of registration institutions for COVID-19 clinical studies.(A)Provinces and municipalities registered for COVID-19 clinical research in China;(B)Registered Unit of Hubei Province.

Figure3.Statistics chart of research frequency of CMT therapeutic drugs.

Figure4.Statistics chart of research frequency of BI therapeutic drugs 
Guangxi Province

Guizhou Province

Heilongjiang Province

Liaoning Province

Shandong Province

Jilin Province

Shanxi Province

Tianjin

Anhui Province

Jiangsu Province

Fujian Province

Henan Province

Hunan Province

Shanxi Province

Jiangxi Province

Chongqing

Shanghai

Beijing

Sichuan Province

Zhejiang Province

Guangdong Province

Hubei Province

0

10

20

30

40

50

60

70

80

Number of registered clinical trials

B

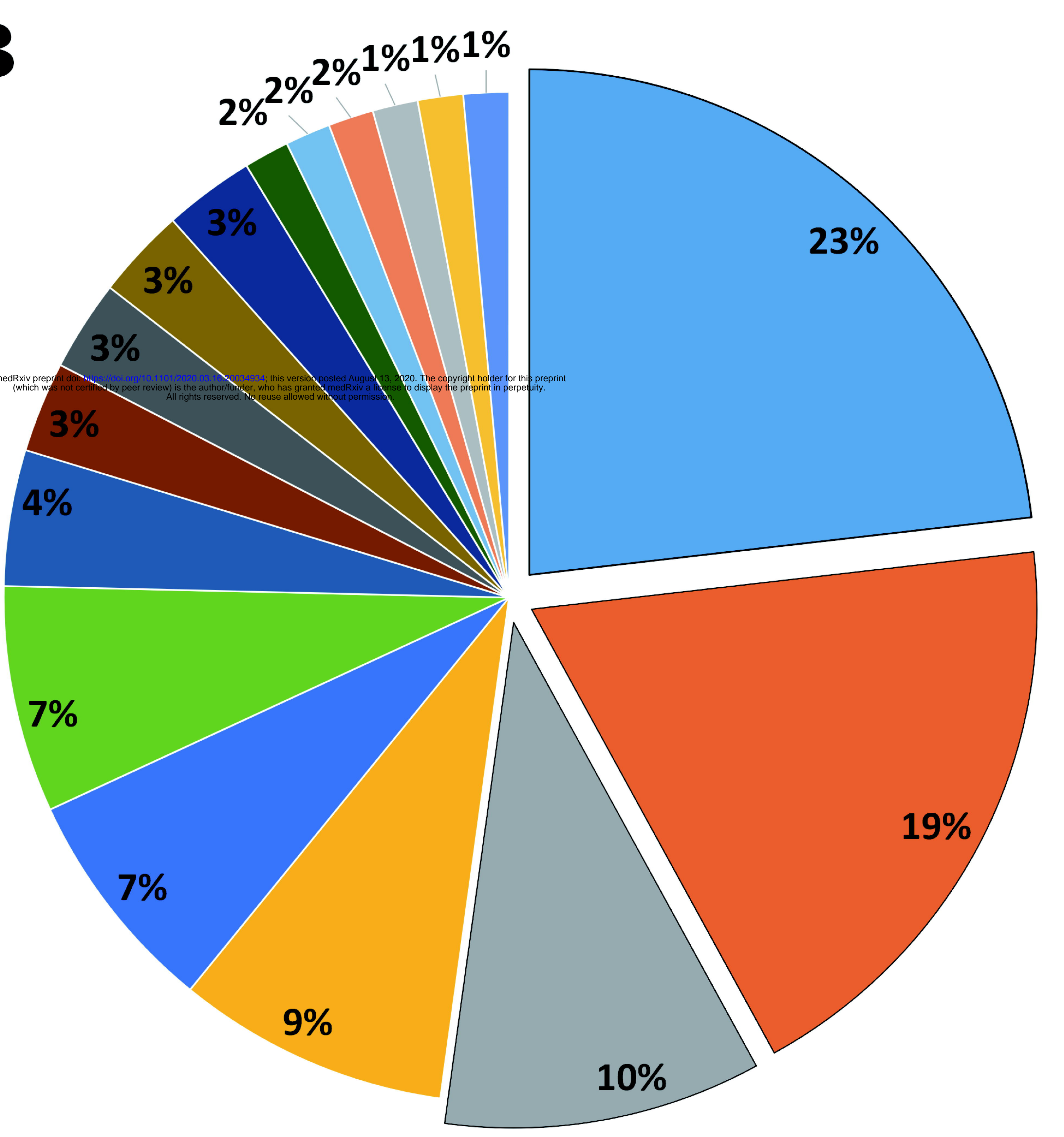

$\square$ Tongji Hospital of Wuhan

Wuhan Union Hospital

$\square$ Zhongnan Hospital of Wuhan University

Renmin Hospital of Wuhan University

Xinhua affiliated hospital

Wuhan Jinyintan Hospital

Hubei Hospital of Traditional Chinese Medicine

- Huangshi Hospital of TCM/Faculty of Rehabilitation Medicine

- Jingzhou Central Hospital

Wuhan Fourth Hospital

- Xiangyang 1st People's Hospital

Hubei Integrated Hospital of Traditional Chinese and Western Medicine

Wuhan 1st Hospital

Wuhan Pulmonary Hospital

- First People's Hospital of Jiangxia District

Wuhan Hospital of Integrated Traditional Chinese and Western Medicine

Wuhan Asia General Hospital 


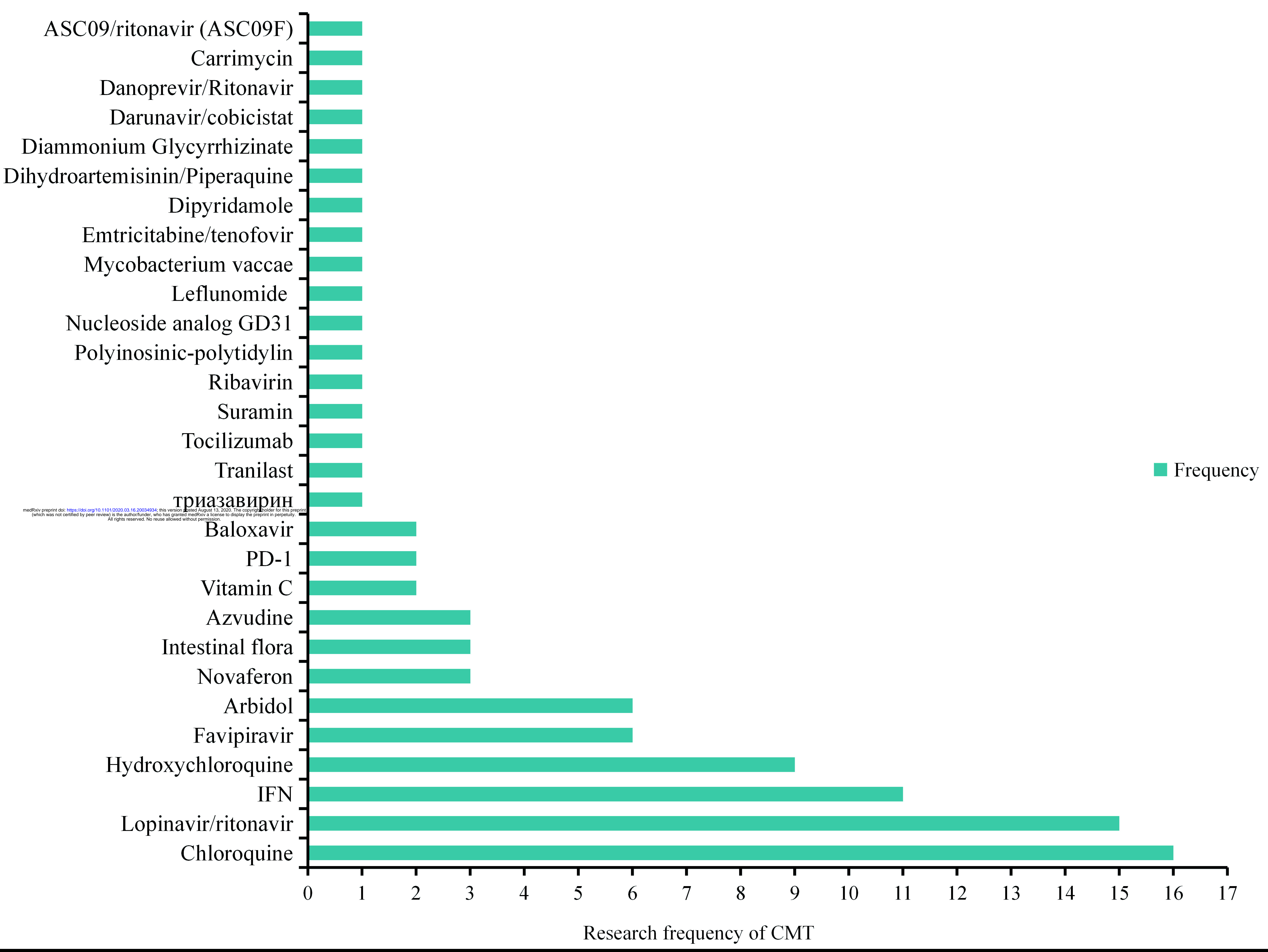




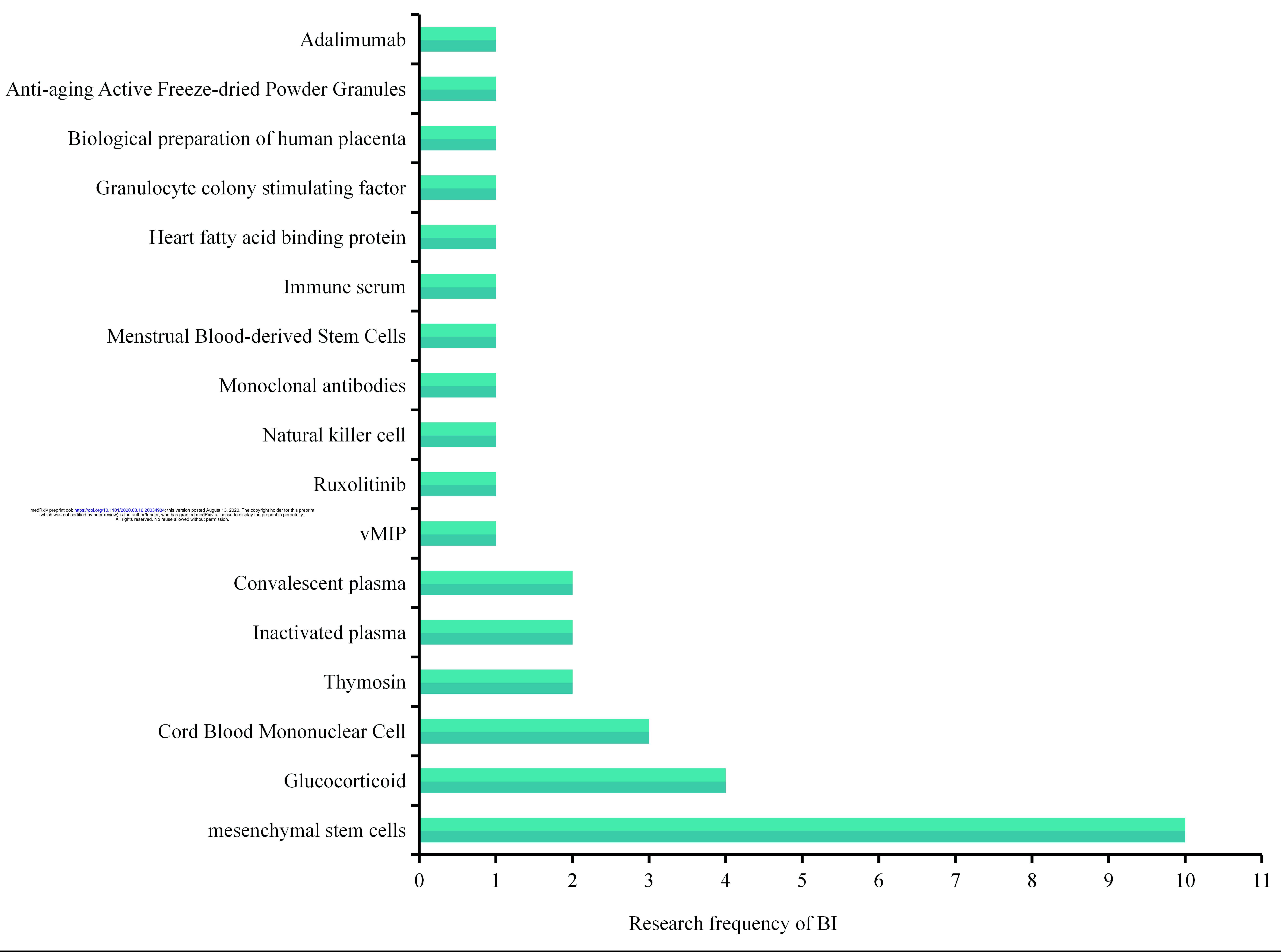

